\title{
Nondestructive characterization of epoxy matrix composites reinforced with Luffa lignocellulosic fibers
}

\author{
Diana Carolina Parada Quinayá ${ }^{1}$, Jose Roberto Moraes D'almeida ${ }^{1}$
}

\footnotetext{
${ }^{1}$ Department of Chemical and Materials Engineering, Pontifical Catholic University of Rio de Janeiro. RJ, Brazil e-mail: dcarolinapq@gmail.com
}

\begin{abstract}
Luffa Cylindrica is a tropical plant from the Cucurbitaceae family, whose fruit becomes very fibrous when fully ripened. The lignocellulosic sponges of Luffa can be suitable for use as reinforcement of epoxy matrix composites, because they have a morphology with spatial 3-D arrangement as well as are eco-friendly materials (biodegradable, and high available) and have economic advantages compared to composites reinforced with synthetic fibers derived from non-renewable sources. Surface modification of the Luffa fibers was carried out by hornification and mercerization methods and was verified by Fourier transform infrared spectroscopy (FTIR), scanning electron microscopy (SEM), and X-Ray Diffraction (XRD). For the fabrication of non-biodegradable composites by hand layup technique, the sponges were impregnated with an epoxy resin based on bisphenol in a metallic mold with dimensions $150 \times 200 \times 3 \mathrm{~mm}^{3}$, followed by compression at $5 \mathrm{MPa}$. The dynamic modulus of the fabricated composites were measured using the nondestructive impulse excitation technique (IET), according to the ASTM E1876 standard. Bar specimens with dimensions $80 \times 25 \times 3 \mathrm{~mm}^{3}$

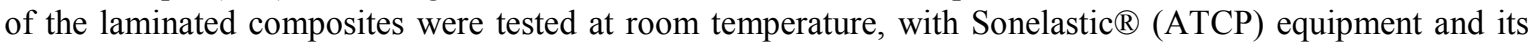
associated software. Results showed that the Luffa/epoxy composites has higher loss factor and dynamic modulus when the Luffa fiber is treated before the composite fabrication. The highest Young's modulus obtained was $4.05 \pm 0.31 \mathrm{GPa}$ for mercerized Luffa/epoxy. For hornificated Luffa/epoxy composite the highest loss factor and shear modulus values obtained, were $0.0337 \pm 0.003$ and $1.46 \pm 0.13$ GPa respectively.
\end{abstract}

Keywords: Sponge gourd, lignocellulosic composite, impulse excitation technique, non-destructive characterization.

\section{INTRODUCTION}

Fiber-reinforced polymer (FRP) industry was developed during the 1940s with the fabrication of composite materials made of a polymer matrix reinforced usually with glass fibers. FRPs products have been used in the aerospace, automotive, marine, construction industries, electrical/electronic and consumer products. However, environmental concerns continue to prompt research into the total or partial replacement of this synthetic reinforcement materials with a rising variety of vegetable fibers with important advantages, besides being biodegradable and non-toxic, of having low cost, low density, good mechanical strength, better noise reduction characteristics, and obtained from renewable sources [2]. Therefore, in recent years, the production of composite using lignocellulosic materials has been investigated and composite panels using lignocellulosic materials, such as bamboo, kenaf, flower stalks, sugarcane bagasse, sisal, pineapple, coir, and pejibaye palm among other [1], [2] have been used. The luffa, also known as loofah or sponge gourd, has a morphology with spatial 3-D arrangement (Fig. 1). The geometric characteristics of luffa sponge depend on several factors, such as place of origin, climate, soil characteristics, etc. Fruits of luffa native of Brazil, are produced with between 10 and $120 \mathrm{~cm}$ in length and $6-15 \mathrm{~cm}$ in diameter. The luffa sponge can be divided into two regions, the core with honeycomb structure and the intermediate wall, which has an inner surface and an outer surface [3]. The intermediate wall can be separated to obtain a natural mat with multidirectional arrangement of fibers. The structure of the inner surface shows that there are two regions with different orientation, one with fibers that grow along longitudinal directions (Fig. 1d) and the other with randomly distributed structure similar to the structure found in the core (Fig. 1e). While in the outer surface can be seen a structure with fibers growing along circumferential directions (Fig. 1f). 

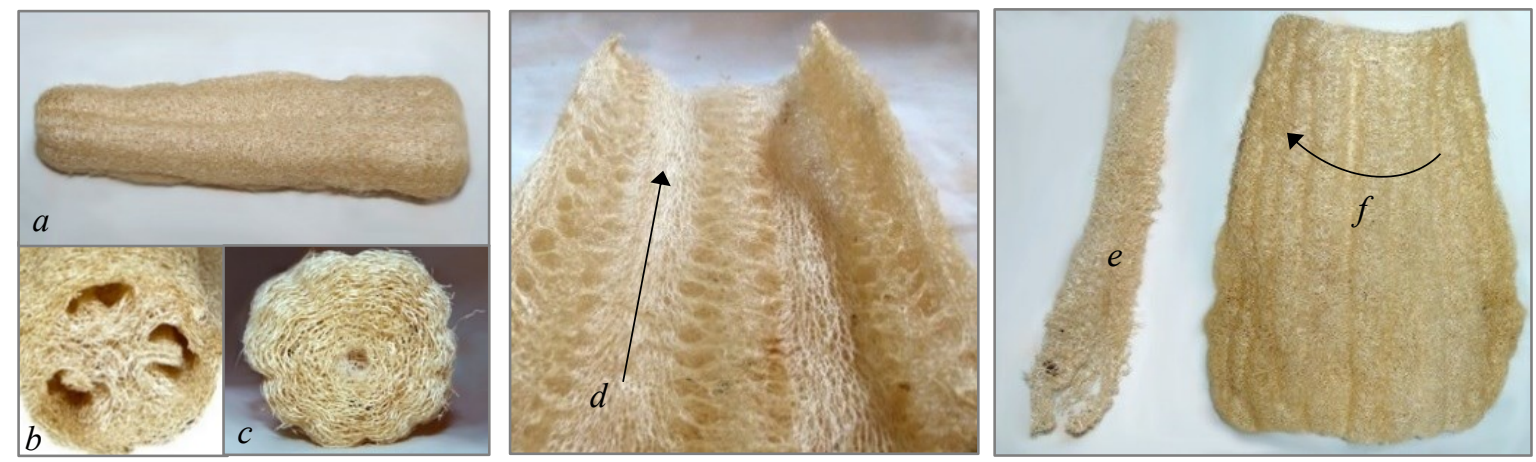

Figure 1: Matured and peeled fruit of luffa gourd, macrostructure and fiber orientation. a) Side view. b) Front view with cut. c) Front view uncut. d) Inner surface. e) Central core. f) External surface.

The composition and microstructure of lignocellulosic fibers generate interfacial phenomena in composite materials that results in a weak interfacial adhesion. Since the main function of the interphase is to facilitate the strain transfer between the fiber and the matrix, natural fiber/epoxy composites can exhibit different mechanical performances and environmental aging resistances depending on their interphase properties.

In this work, two superficial treatment were carried out on luffa fibers native of Brazil. In order to alter the fibers' surface, the sponges were exposed to several cycles of drying and re-wetting known as hornification. During the process, the fiber structure changes and the outer wall of cells collapses. As a result of this effect, the water absorption capacity of the cellulosic fibers decreases irreversibly, due to the formation of hydrogen bonds in cellulose, and allows obtaining beneficial effects when they are incorporated into the matrix [4], [5]. Also, the surface modification with $\mathrm{NaOH}$ was performed, with the purpose of improving the mechanical interlock with the matrix. This treatment, called mercerization, produces morphological changes by removing the outer surface of the fibers and to exposing the inner fibrillar structure, and a correlated increase of roughness and of the contact area of the fibers [6].

The impulse excitation technique (IET) is a non-destructive technique for mechanical evaluation of isotropic materials, through the measure of the natural frequency of vibration of specimens with regular geometry. The specimens are excited by means of a mechanical impact of short duration, followed by capture of the acoustic response by a sensor in accordance with the imposed boundary conditions. The principle of this dynamic method is based on the relationship between the elastic properties of materials with its natural resonant frequency and geometric parameters (dimensions, mass). The present work is focused on experimental determination of elastic and damping properties of luffa/epoxy resin composites using impulse excitation technique (IET). Flexural and torsional modes of vibration were used. The first allows the calculation of Young's modulus and the latter allows the determination of the shear modulus and Poisson's ratio. Moreover, the amplitude decay of the free vibration is related to the damping or internal friction of the material.

\section{EXPERIMENTAL}

\subsection{Materials}

Epoxy resin matrix (MC 150/5), originating from the epichlorohydrin reaction with bisphenol A, together with the hardener FD 144 (primary cycloaliphatic polyamine), was used as matrix. Mats of luffa fibers were used as the lignocellulosic material reinforcement of composites. To remove the adhered impurities, the sponges were washed with water for 2 hours and dried in an oven at $60{ }^{\circ} \mathrm{C}$ until a constant weight was attained, prior to the surface modification process. For the chemical modification of luffa fibers sodium hydroxide $97 \%$ (analytical grade) supplied by Sigma-Aldrich was used. The diameter of cross section was measured by digital processing of SEM images, using ImageJ software.

\subsection{Fiber Modification}

For the hornification process, the fibers were placed in a container with water at $100^{\circ} \mathrm{C}$ for three hours, until they reached their maximum absorption capacity. Then the drying process was carried out in a furnace at $80^{\circ} \mathrm{C}$ for 24 hours. This procedure was repeated five times. For mercerization, the fibers were immersed in aqueous $\mathrm{NaOH}$ solution $2 \%$ by weight for 90 min, rinsed and finally were dried in an oven at $80^{\circ} \mathrm{C}$ until a 
constant weight was obtained. Fiber segments from the external surface of luffa sponge were analyzed by SEM. Surface modification of fibers was verified also by FTIR and DRX. The fibers were previously milled to obtain a fine powder for the analysis. FTIR analysis was performed using a PerkinElmer Spectrum ${ }^{\mathrm{TM}} 400$ infrared spectrophotometer in the region between 500 and $4000 \mathrm{~cm}^{-1}$, operating with a scan rate of $0.2 \mathrm{~cm} / \mathrm{s}$, at room temperature, with an attenuated total reflectance (ATR) accessory. The X-ray diffraction patterns of the fibers, with and without modification, were obtained by means of a Bruker D8 Discover X-ray diffractometer operating with $\mathrm{CuK}_{\alpha}$ radiation $=1.5418 \AA$, values of $2 \theta$ varying from $5^{\circ}$ to $70^{\circ}$ and step of $0.02^{\circ}$ (step time of 0.3 seconds). The crystalline index $\left(W_{c}\right)$ was calculated by the area method, using the equation 1 , which express the ratio between the total area of crystalline regions $\left(A_{\text {cryst }}\right)$ and the total area of the curve $\left(A_{t o-}\right.$ tal) [7]. The amorphous and crystalline areas were measured by deconvolution of the peaks in a proper software.

$$
W_{C}(\%)=\frac{A_{\text {cryst }}}{A_{\text {total }}} \times 100
$$

\subsection{Composites fabrication and characterization}

Preparation of epoxy matrix composites with $20 \%$ weight fraction of luffa was made by hand layup technique. Previously pressed fiber sheets were impregnated in the mixture of epoxy resin components (at a ratio 100:20). Then, the fibers were distributed in different directions in a metallic mold with dimensions $150 \times 200 \times 3 \mathrm{~mm} 3$, in order to obtain an isotropic structure, and it was subsequently applied $5 \mathrm{MPa}$ of pressure using a hydraulic press. The composites were cured at room temperature. Specimens made from epoxy resin without fibrous reinforcement were also prepared. The mechanical properties of the fabricated composites were measured using the nondestructive impulse excitation technique (IET).

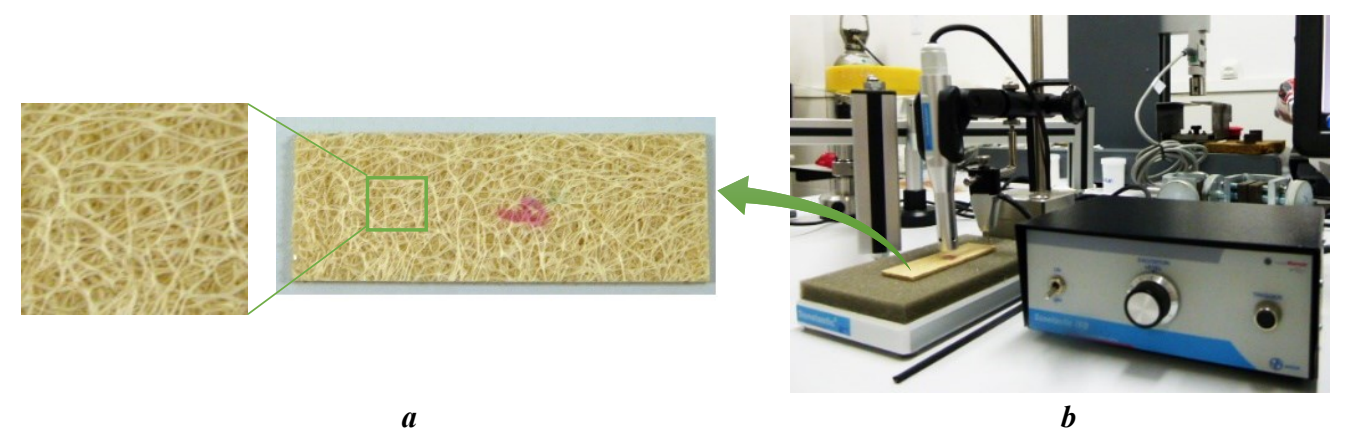

Figure 2: a) Luffa fiber/epoxy composite specimen $\left(80 \times 25 \times 3 \mathrm{~mm}^{3}\right)$. b) Automatic electromagnetic pulser developed by ATCP by impulse excitation method.

The dimensions and mass of specimens (Fig. 2a) were measured and the specimens were tested with Sonelastic ${ }^{\circledR}$ (ATCP) equipment and its associated software at room temperature. Initially the specimen was properly positioned and the desired contour conditions (flexural and torsional modes of vibration) were selected. Then, the specimens were excited with an electromagnetic pulser (Fig. 2b), and the acoustic response was captured and processed by the software and a mathematical treatment was done for obtaining a frequency spectrum (Fourier Transform). The flexural and torsional resonant frequencies of the composites were determined, and the elastic modulus (E), shear modulus $(\mathrm{G})$ and the Poisson's ratios $(v)$, were then calculated according to the standard ASTM E1876, for the rectangular bar specimens. The measurements were repeated for each specimen until obtain ten consecutive readings of frequency and damping, within $1 \%$ of each other. The average frequency of the readings was taken as the resonant frequency of the specimen. After that, the resonant frequency readings of specimens containing the same type of fiber luffa were averaged to obtain the resonant frequency of each composite.

\section{RESULTS AND DISCUSSION}

Through the analysis of the fibers by SEM, it was found that luffa fibers have a rounded cross-section with variable diameter, and are composed of individual cells with a central lumen (Fig. 3). An average diameter of $0.395 \pm 0.041 \mathrm{~mm}$ and an average of area of $0.067 \pm 0.018 \mathrm{~mm} 2$ for the cross section were measured. The SEM micrographs of the untreated fibers displays some non-fibrous components scattered over the surface (Fig. 4a), which were efficiently removed by the subsequent treatments. The removal of non-cellulosic constituents after the hornification process by the effect of 5 cycles of drying and rewetting is shown in the mi- 
crograph of Fig. 4b. Alkali modification, caused the hydrolysis of hemicellulose and the resulting surface is shown in the micrograph of Fig. 4c. In Fig.5, are presented the FTIR spectra corresponding to treated and untreated luffa fibers. All fibers exhibited an absorption band in the region between 3650 and $3250 \mathrm{~cm}-1$, common to lignocellulosic materials. The enlargement of this peak is due to the contribution of water absorption and the presence of hydrogen type interactions. The absorption peak at $1742 \mathrm{~cm}-1$, which does not appear in $\mathrm{NaOH}$ treated luffa fibers spectrum, suggests a significant deesterification of the fibers and the removal of esters linked with aromatic ring of lignin. Likewise, it can be seen that non mercerized fibers show a peak of lower absorption around $1231 \mathrm{~cm}-1$ that has been eliminated due to treatment with $\mathrm{NaOH}$, and may be associated with the stretching of the $\mathrm{C}-\mathrm{O}$ and $\mathrm{C}-\mathrm{O}-\mathrm{C}$ bonds, present in the glycosidic linkage, from lignin. Absorption peaks observed in $1627 \mathrm{~cm}-1$ and $1635 \mathrm{~cm}-1$ may correspond to $\mathrm{C}-\mathrm{C}$ bonds of aromatic rings typically present in the lignin macromolecule. The peaks appearing at 1381 and $1384 \mathrm{~cm}-1$, respectively, are due to vibration of $\mathrm{C}-\mathrm{H}$ bond of cellulose structure.
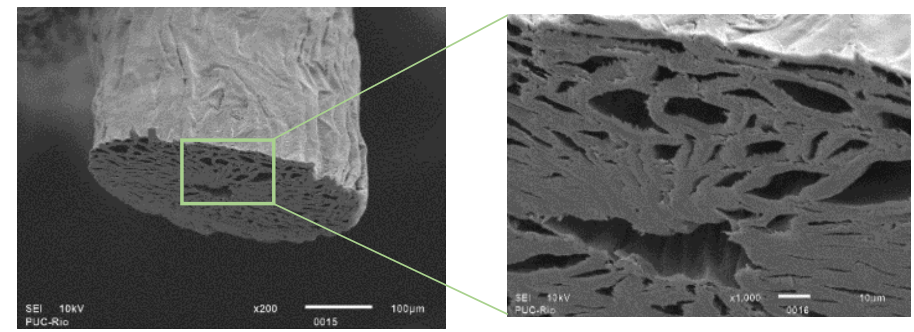

Figure 3: Luffa fiber cross section 200x. Detail: Lumen and micro cells 1000x.
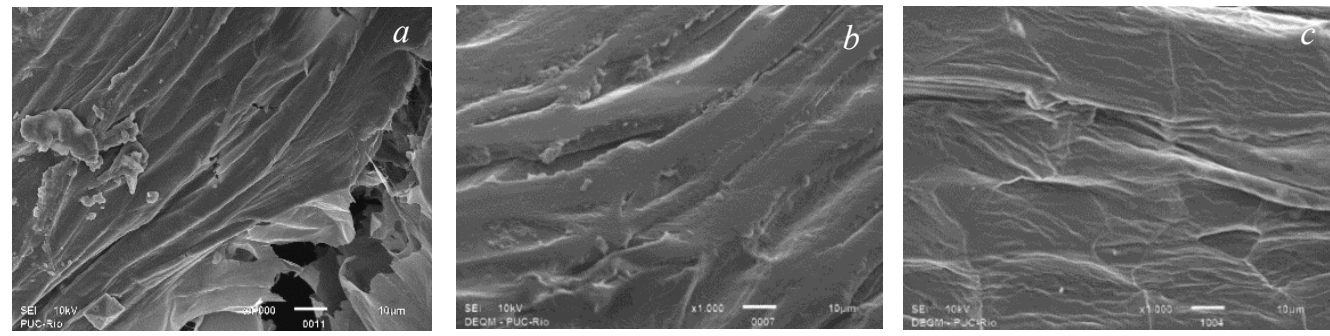

Figure 4: SEM images for luffa fibers surface (1000x). a) Untreated. b) Hornificated luffa fibers c) Mercerized luffa fibers $(\mathrm{NaOH} 2 \%, 90 \mathrm{~min})$.

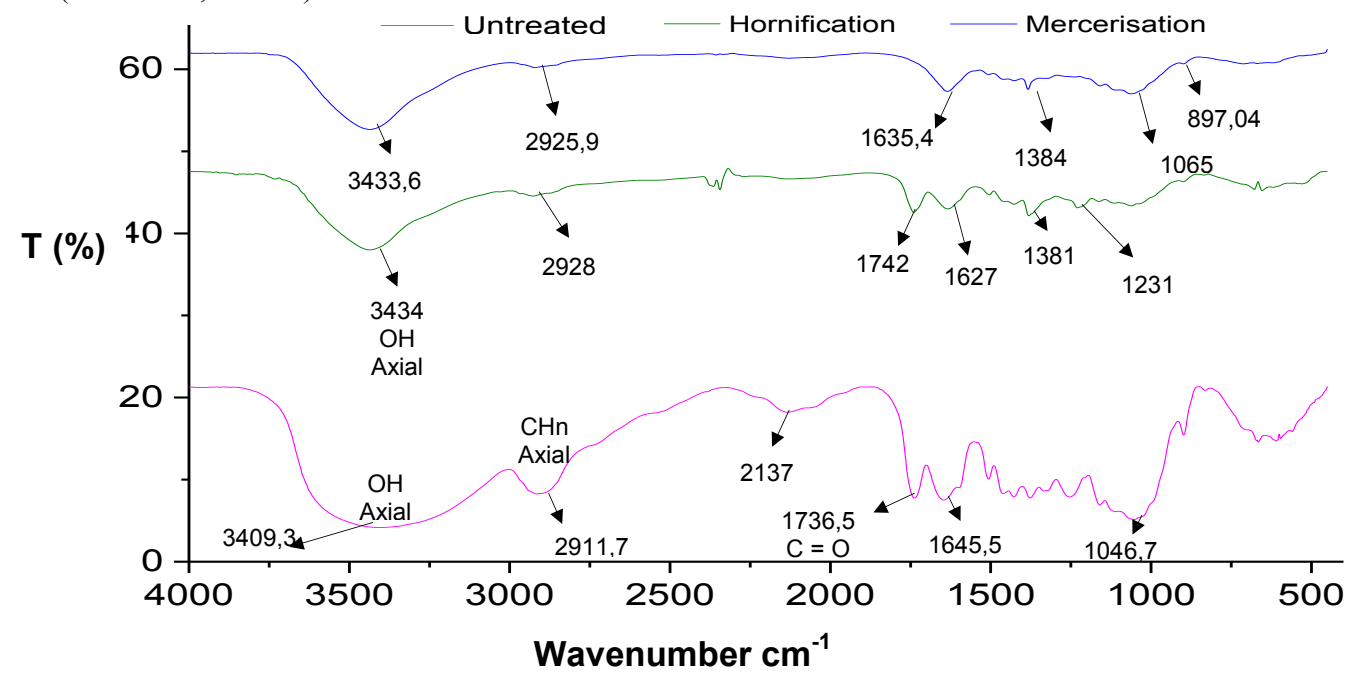

Figure 5: FTIR Spectrum of luffa fiber as received and with the different treatments.

Fig. 6 shows the X-ray diffractogram of the luffa fibers analyzed. Three distinct peaks are observed, indicating that the fibers have partially crystalline and amorphous characteristics. The first peak indicates the presence of native cellulose on crystallographic plane (101) whereas the peak around $22^{\circ}$ indicates the diffraction of crystalline cellulose or cellulose I in the crystallographic plane (002). The peak around $34^{\circ}$ corre- 
sponds to the diffraction in the plane (040) [8].

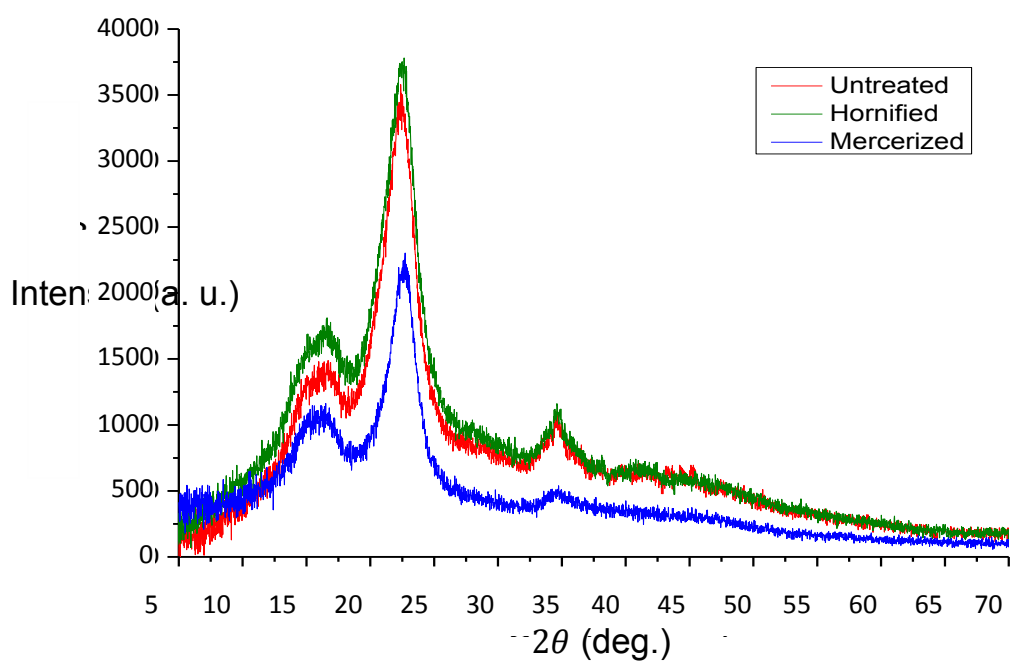

Figure 6: XRD pattern for luffa fiber

The determined crystalline index values are shown in Table 1 . The lower crystallinity value of untreated luffa fiber is attributed to the presence of non-cellulosic compounds. For the treated fibers with hornification method there is a slight increase of crystallinity, compared with untreated luffa values, suggesting therefore a possible change in the amorphous region, caused by packing of the cellulose chains [9]. The mercerized luffa fibers showed a different behavior, associated with the decrease of the amorphous content in the samples after modification. The XRD spectra suggest the removal of a significant amount of hemicelluloses and non-cellulosic polysaccharides during the alkaline treatment.

Table 1: Degree of crystallinity of luffa fibers.

\begin{tabular}{l|l|l|l|l}
\hline & \multicolumn{1}{|c|}{$\begin{array}{c}\text { UNTREATED LUFFA } \\
\text { FIBER }\end{array}$} & $\begin{array}{c}\text { HORNIFICATED } \\
\text { LUFFA FIBER }\end{array}$ & $\begin{array}{c}\text { MERCERIZED LUFFA } \\
\text { FIBER }\end{array}$ \\
\hline Total area & {$[\mathrm{cps} \times \mathrm{deg}]$} & 19770 & 20270 & 9681 \\
\hline Crystalline area & {$[\mathrm{cps} \times \mathrm{deg}]$} & 8864 & 9349 & 5407 \\
\hline Crystallinity & $\%$ & 44.83 & 46.12 & 55.85 \\
\hline
\end{tabular}

ANOVA analysis indicate a significant difference in the values of $\mathrm{E}$ and $\mathrm{G}$ for composites made with untreated and treated fibers. This results, shown in Figure 7, indicate that the modification treatments have influence on dynamic modulus of the composites evaluated. However, the intensity of this improvement was independent of the type of treatment performed, i.e. there was no significant statistical difference between the dynamic modulus values obtained for composites with hornification and mercerization treatments.

The impulse excitation method was also used to measure the damping the test specimens. The damping $(\xi)$ corresponds to the oscillation decay rate (Fig 8a), and characterizes how fast decays the vibration amplitude after the mechanical excitation. This property is directly related to the internal mechanisms of energy dissipation, like internal friction, and is normally quantified by the loss factor or Tan $(\varphi)$.

The dynamic elastic modulus (E), dynamic shear modulus (G), Poisson's ratio $(\mu)$, loss factor, flexural resonant frequency $\left(f_{f}\right)$ and torsional resonant frequency $\left(f_{T}\right)$ results for luffa fiber/epoxy resin composites, along with the density $(\rho)$ results are presented in Table 2 . The dynamic elastic and shear modulus values of epoxy composites increased compared with the epoxy resin without luffa fibers as reinforcement phase. 

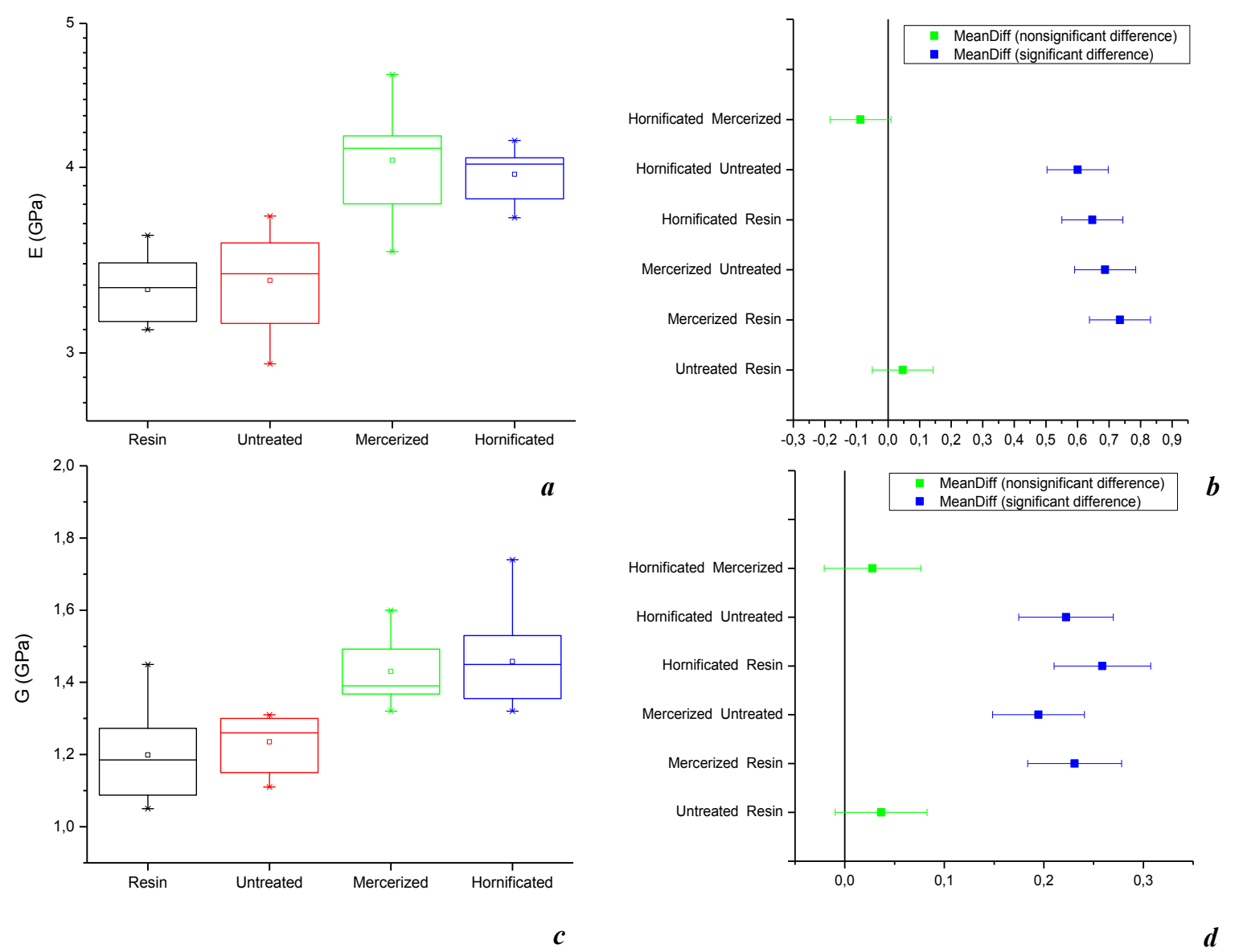

Figure 7: Dynamic modulus in flexure from epoxy resin, untreated and treated composites. a) Young's modulus (E) b) Tukey test results for E, with significance level of 0.05 c) Shear modulus $(G)$ d) Tukey test results for G, with significance level of 0.05 .

Figure $8 \mathrm{~b}$ show the stiffness-loss map, E vs. $\tan \varphi$ of the evaluated composites. It is noted that the loss factor values obtained for the epoxy resin were the highest, compared with the damping values for composites with treated and untreated fiber reinforcement. Besides, the untreated luffa fiber composite showed the lowest modulus as well as lowest $\tan \varphi$. Figure 9 shown the results of the loss factor of epoxy and composite specimens, and Tukey test results for ANOVA analysis, which indicated no statistically significant differences for the damping values of composites made with fibers modified with hornification and mercerization treatments.

Table 2: Experimental data on resonant frequencies, elastic modulus and the calculated Poisson's ratio for the composites investigated

\begin{tabular}{l|l|l|l|l|l}
\hline & & EPOXY RESIN & $\begin{array}{l}\text { UNTREATED } \\
\text { LUFFA FIBER }\end{array}$ & $\begin{array}{l}\text { HORNIFICATED } \\
\text { LUFFA FIBER }\end{array}$ & $\begin{array}{l}\text { MERCERIZED } \\
\text { LUFFA FIBER }\end{array}$ \\
\hline$\rho$ & {$\left[\mathrm{g} / \mathrm{cm}^{3}\right]$} & 1,10 & 0,95 & 1,06 & 1,02 \\
\hline$f_{f}$ & {$[\mathrm{~Hz}]$} & 774,72 & 879,88 & 961,07 & 924,38 \\
\hline$f_{T}$ & {$[\mathrm{~Hz}]$} & 1440,80 & 1616,93 & 1755,94 & 1824,04 \\
\hline$E$ & {$[\mathrm{GPa}]$} & $3,31 \pm 0,16$ & $3,36 \pm 0,24$ & $3,96 \pm 0,16$ & $4,05 \pm 0,31$ \\
\hline$G$ & {$[\mathrm{GPa}]$} & $1,20 \pm 0,12$ & $1,23 \pm 0,07$ & $1,46 \pm 0,13$ & $1,43 \pm 0,09$ \\
\hline Loss factor & & $0,039 \pm 0,004$ & $0,031 \pm 0,003$ & $0,034 \pm 0,003$ & $0,033 \pm 0,001$ \\
\hline$\mu$ & & $0,38 \pm 0,11$ & $0,34 \pm 0,07$ & $0,34 \pm 0,06$ & $0,35 \pm 0,07$ \\
\hline
\end{tabular}



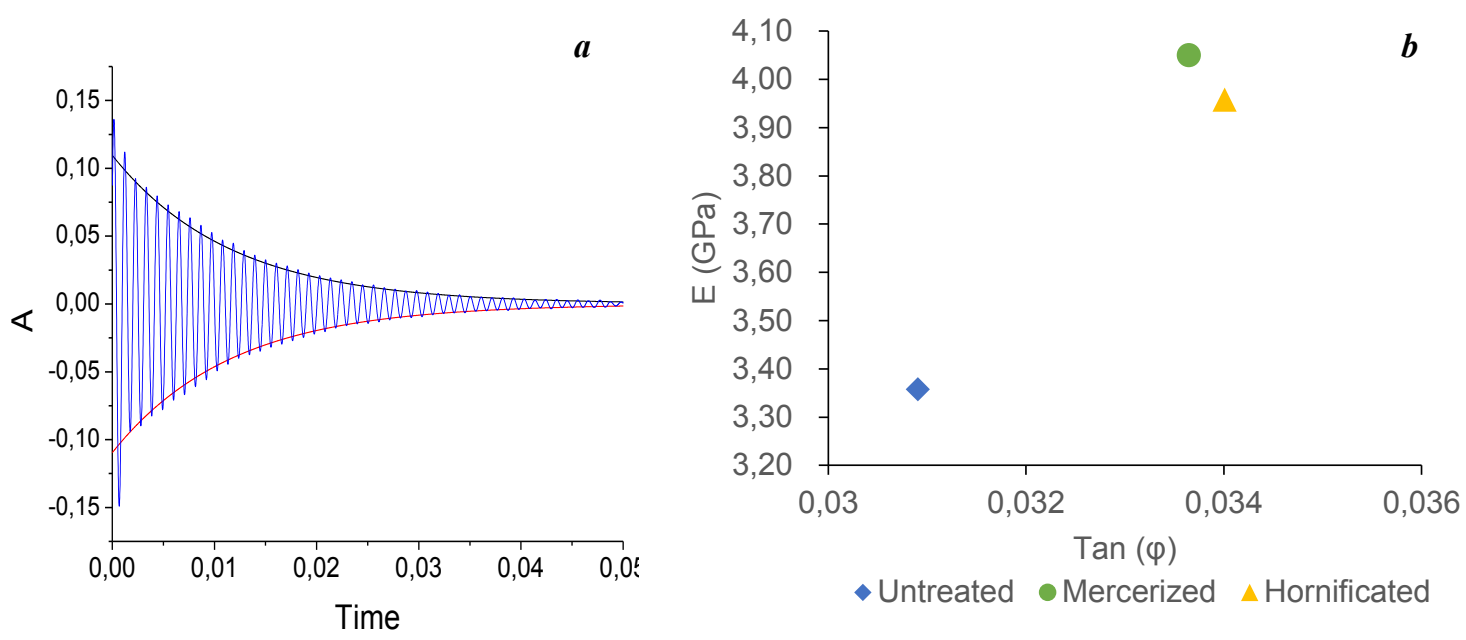

Figure 8: a) Signal on resonance time for luffa/epoxy composite after excitation by mechanical impulse. b) stiffness-loss map of the evaluated composites.

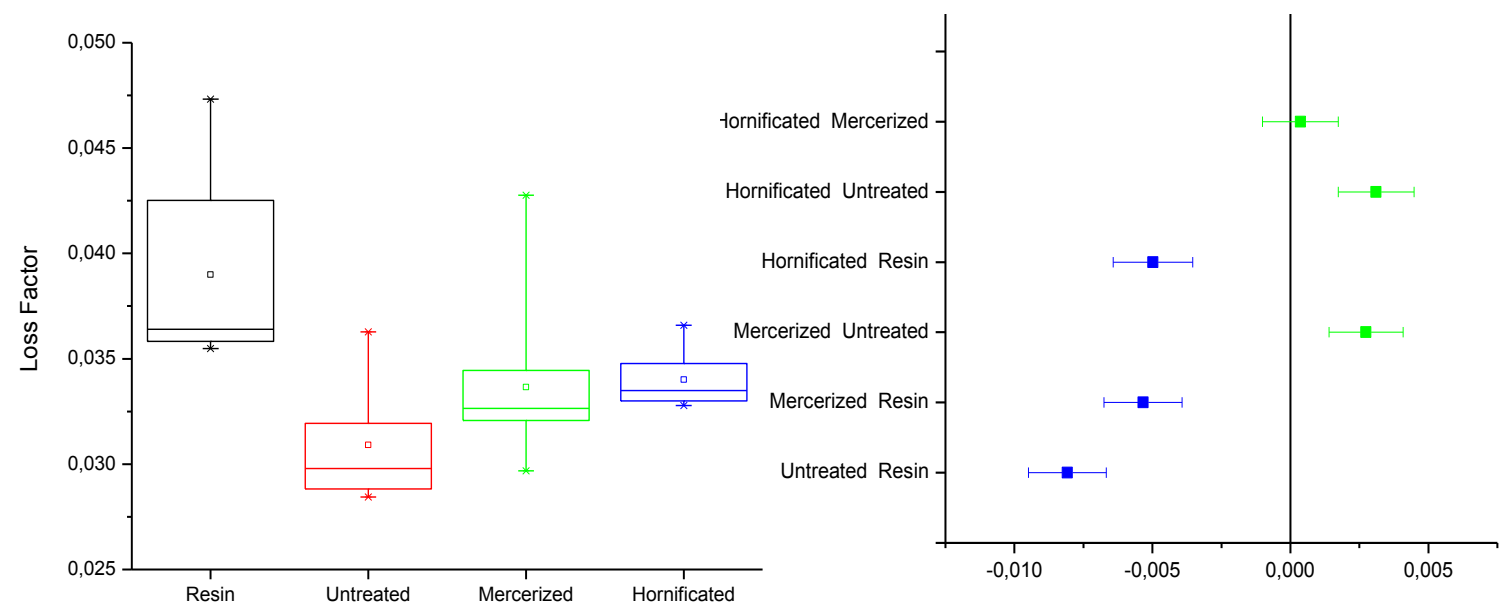

Figure 9: $a$ ) Loss factor from epoxy resin and composites.) b) Tukey test results, with significance level of 0.05

\section{CONCLUSIONS}

Fiber segments from the external surface of luffa sponge analyzed by SEM, allowed the evaluation of the cross section and allowed detailed examination of the surface morphology of luffa fibers, enabling to assess the effects of the treatments performed. The major components of luffa fibers are based on cellulose, hemicellulose and lignin, and the observed features at FTIR spectra were mainly attributed to these components. The observed changes in the magnitude of the signals in FTIR spectra on fiber surface of luffa fibers modified, allowed to verify the efficiency of surface treatments performed. The efficient removal of non-cellulosic components from the amorphous regions during the performed treatments, was also verified, and higher values of crystallization were obtained for the treated fibers. The impulse excitation technique, provides an effective method for the characterization of composite materials. Damping of evaluated composites showed a direct relationship with frequency. Loss factor values were increased with increasing of natural frequencies and a similar effect is observed for the variation in shear modulus values. The results showed the influence of modification caused by superficial treatments on the dynamic modules and damping values of the composites evaluated. It was found that the elastic modulus values are higher in those composites made from fibers treated with mercerization and hornification. The loss factor values, that are indicatives of the energy dissipated, were modified by the incorporation of fibers, but without a significant variation caused by the type of treatment used. 


\section{ACKNOWLEDGEMENTS}

The authors acknowledge the financial support from the Brazilian Agency CAPES.

\section{BIBLIOGRAPHY}

[1] FARUK, O., BLEDZKI, A., FINK, P., SAIN, M. "Biocomposites reinforced with natural fibers: 2000 2010", Progress in Polymer Science, v. 37, n 11, pp. 1552-1596, 2012.

[2] QUINAYÁ, D. C. P., SILVA, E. S., D'ALMEIDA, J. R. M. "On the Use of Residues from the Sustainable Extraction of Heart of Palm in Agglomerated Panels", Journal of Natural Fibers, v. 13, n. 2, pp. 172-177, 2016.

[3] BOYNARD, C. A., D'ALMEIDA, J. R. M. "Morphological characterization and mechanical behavior of sponge gourd (luffa cylindrica)-polyester composite materials", Polymer-Plastics Technology and Engineering, v. 39, n. 3, pp. 489-499, 2000.

[4] MEJIA, J., FIORELLI, J., SAVASTANO, H. "Evaluation of the Effect of Drying and Rewetting Cycles in Eucalyptus Pulps", IACSIT International Journal of Engineering and Technology, v. 7, n. 5, 2015.

[5] FERREIRA, S. R., LIMA, P. R. L., SILVA, F. A. "Effect of Sisal Fiber Hornification on the Fiber-Matrix Bonding Characteristics and Bending Behavior of Cement Based Composites," Key Engineering Materials, v. 600, pp. 421-432, 2014.

[6] BOYNARD, C. A., MONTEIRO, S. N., D'ALMEIDA, J. R. M. "Aspects of Alkali Treatment of Sponge Gourd (Luffa cylindrica) Fibers on the Flexural Properties of Polyester Matrix Composites," Journal of Applied Polymer Science, v. 87, n 12, pp. 1927-1932, 2003.

[7] M. Y. IOELOVICH and G. P. VEVERIS, "Determination of Cellulose Crystallinity by X-ray Diffraction Method", J. Wood Chemistry, v. 5, pp. 72-80, 1987.

[8] M. WADA., T. OKANO, "Localization of I $\alpha$ and I $\beta$ phases in algal cellulose revealed by acid treatments", Cellulose, v. 8, n 3, pp. 183-188, 2001.

[9] K. SOMWANG, T. ENOMAE, A. ISOGAI and F. ONABE, "Changes in Crystallinity and Re-swelling Capability of Pulp Fibers by Recycling Treatment”, After Japan Tappi Journal, v. 56, n. 6, pp. 863-869, 2002. 